\title{
Profile of common inflammatory markers in treatment-naïve patients with systemic rheumatic diseases
}

\section{Min Jung Kim}

Seoul National University College of Medicine https://orcid.org/0000-0002-2618-1415

\section{Eun Bong Lee}

Seoul National University College of Medicine

\section{Yeong Wook Song}

Seoul National University College of Medicine

Jin Kyun Park ( $\square$ jinkyunpark@gmail.com )

https://orcid.org/0000-0003-2167-9393

\section{Research article}

Keywords: inflammatory marker, WBC, ESR, CRP, rheumatic disease, cytokine

Posted Date: January 13th, 2020

DOI: https://doi.org/10.21203/rs.2.20755/v1

License: (c) (i) This work is licensed under a Creative Commons Attribution 4.0 International License.

Read Full License

Version of Record: A version of this preprint was published at Clinical Rheumatology on April 20th, 2020. See the published version at https://doi.org/10.1007/s10067-020-05049-9. 


\section{Abstract}

\section{Background}

The host inflammatory response against infection is characterized by leukocytosis, and the release of cytokines and acute phase proteins. However, routine inflammatory markers are not always elevated in systemic rheumatic diseases (SRD). Here, we aimed to systematically evaluate and compare the clinical implications of common inflammatory markers in systemic rheumatic diseases (SRDs).

\section{Methods}

We investigated the profiles of erythrocyte sedimentation rate (ESR), C-reactive protein (CRP) and white blood cell (WBC) count in treatment-naïve patients with SRDs, osteoarthritis and pneumonia diagnosed at Seoul National University Hospital during 2004-2016. SRDs included rheumatoid arthritis (RA), systemic lupus erythematosus (SLE), ankylosing spondylitis (AS), systemic sclerosis (SSc), idiopathic inflammatory myopathy (IIM) and adult onset of Still disease (AOSD). Associations between inflammatory markers were evaluated using Pearson's correlation and regression analysis. Differences between correlations were compared using Steiger's z-test. Receiver operating characteristic (ROC) curve analysis was performed to examine the predictive value of inflammatory markers for SRD diagnosis.

Results

We identified 1191 patients with SRDs, osteoarthritis and pneumonia. Leukocytosis was present in $<15 \%$ SRD patients. There was marked variability in ESR and CRP levels among different SRDs. The highest mean CRP levels (mean $\pm \mathrm{SD}, \mathrm{mg} / \mathrm{dL}$ ) were observed in those with AOSD (11.3 \pm 7.9 ), followed by RA (2.0 \pm 3.3$)$, IIM (1.8 \pm 3.5$)$, SLE (1.5 \pm 3.1$)$, SSc $(0.6 \pm 1.3)$ and AS $(0.08 \pm 0.1)$. Mean ESR (mm/hr) was also

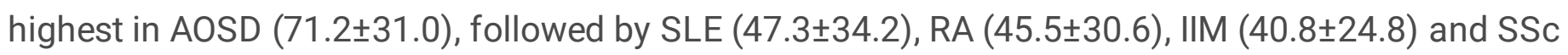
(27.8 \pm 26.0$)$. All SRDs showed significant positive correlations between ESR and CRP: greatest in RA $(r=0.53, p<0.001)$ and weakest in SLE $(r=0.20, p=0.03)$. WBC correlated weakly with CRP but not with ESR in most SRDs. While the AUC for WBC count (0.54-0.68) was less than that of ESR or CRP, the AUC for ESR and CRP (0.69-0.86) were similar in SRD. The optimal cuff-off values for inflammatory markers predicting SRD were within or slightly above the normal limit.

\section{Conclusions}

Unlike acute infection, ESR, CRP and WBC count are not always elevated in treatment-naïve patients with SRD. Thus, common inflammatory markers have limited value for diagnosis and assessment of disease activity of SRD.

\section{Background}

Inflammation is a generic but efficient response to external and internal injuries such as infection, trauma and cancer; the ultimate goal is to eliminate the insult and repair damaged tissue (1). Increased 
production of proteins required for host defence (so-called acute phase proteins) in the liver, and mobilisation of white blood cells (WBC) from the bone marrow to sites of inflammation, are the major humoral and cellular, respectively, inflammatory responses; both are orchestrated by inflammatory cytokines and chemokines released initially at the site of injury $(2,3)$. As a result, C-reactive protein (CRP), erythrocyte sedimentation rate (ESR) and WBC counts are elevated during an acute infection. These are surrogate markers of inflammation, which can be used to measure the extent of systemic inflammatory responses in patients with infection or inflammatory diseases.

However, leukocytosis occurs in only $27 \%$ of patients with rheumatoid arthritis (RA), and CRP levels in patients with active systemic lupus erythematosus (SLE) are elevated only slightly (4-6). In addition, elevated ESR in those with dermatomyositis (DM) is not associated with the extent of muscle inflammation but rather with the presence of pulmonary involvement (7). Thus, patients with systemic rheumatic diseases (SRDs) rarely show elevation of CRP, ESR and WBC counts, leading clinicians to question their clinical role as surrogate markers for evaluating the extent of systemic inflammation in SRD. Here, we aimed to systematically investigate the CRP, ESR and WBC counts in treatment-naïve patients with SRD, and to re-evaluate their clinical implications.

\section{Methods}

\section{Patients}

Patients aged 18 years or older, who had received a diagnosis of SRD at Seoul National University Hospital from January 2004 to December 2016, were included in this retrospective study. SRD included RA, SLE, ankylosing spondylitis (AS), systemic sclerosis (SSc), adult onset Still's disease (AOSD) and idiopathic inflammatory myopathy (IIM). Diagnosis of each SRD was based on the following criteria: the 1987 American College of Rheumatology (ACR) criteria (8) or the 2010 ACR/European League Against Rheumatism (EULAR) criteria for RA (9); the 1997 ACR criteria for SLE (10); the 1984 modified New York criteria for AS (11); the 2013 ACR/EULAR criteria for SSc (12); Yamaguchi's criteria for AOSD; (13); and the Bohan and Peter criteria for IIM (14). Patients with osteoarthritis (OA) and patients with pneumonia, who were treated during the same period at Seoul National University Hospital, were included as a control for non-inflammatory disease and acute bacterial infection, respectively. Patients with incomplete laboratory data or comorbidities (active infection, cancer or haematological, renal and liver disease) that have a marked effect on inflammatory markers were excluded. The study complied with the Declaration of Helsinki and was approved by the Institutional Review Board of Seoul National University Hospital (H1702-064-831). The requirement for informed consent was waived due to the retrospective nature of study.

\section{Data collection}

Demographic (age, gender and medical history) and laboratory data were obtained from electronic medical records. Laboratory data included WBC counts with differential counts (absolute neutrophil, lymphocyte and monocyte counts), haemoglobin levels, platelet counts and serum ESR, CRP and albumin 
levels at the time of diagnosis (before the start of treatment). This should eliminate the effects of treatment on inflammatory markers. In addition, disease-specific autoantibodies, human leukocyte antigen (HLA)-B27 and other laboratory parameters of disease activity were collected.

\section{Measurement of routine inflammatory markers}

A complete blood count with differential counts was performed using an automatic haematology analyser (ADVIA 2120i Hematology System with Autoslide; Siemens Healthineers, Erlangen, Germany). Serum ESR levels were measured using the TEST-1 SDL (ALIFAX SPA, Padova, Italy). Serum CRP levels were measured using a latex-enhanced turbidimetric immunoassay with a high sensitive CRP-Latex reagent (Denka Seiken, Tokyo, Japan); data were analysed using a chemistry autoanalyser. All laboratory investigations were conducted in the Department of Laboratory Medicine at Seoul National University Hospital.

\section{Statistical analyses}

SRDs were compared using Student's t-test or analysis of variance with Bonferroni correction (continuous variables) or the Chi-square or Fisher's exact test (categorical variables), as appropriate. The strength of the association between WBC count, ESR and CRP levels in each SRD were evaluated using Pearson's correlation. Steiger's z-test was used to test for significant differences between the Pearson correlation coefficients. For this, correlation coefficients were transformed into z-scores. Linear regression analysis, adjusted for age and gender (both of which affect CRP and ESR levels) (15-17), of inflammatory markers was performed when the Pearson's correlation test was statistically significant. The predictive value of inflammatory markers for discriminating between each SRD and OA (a control for non-inflammatory disease) was evaluated using receiver operator characteristic (ROC) analysis and by calculating the area under the curve (AUC) and the $95 \%$ confidence interval (Cl). Statistical analyses were performed using SPSS version 22.0 (IBM SPSS statistical software, Chicago, IL, USA) and R-3.3.1 software. A p-value < 0.05 was considered statistically significant.

\section{Results}

\section{Patient characteristics}

A total of 1191 patients were included in the study: 268 RA, 150 SLE, 110 SSc, 126 IIM (112 DM and 14 polymyositis (PM)), 200 AS and 107 AOSD. In addition, 130 OA and 100 pneumonia patients were enrolled as controls. As expected, patients with AS and SLE were younger at diagnosis than those with RA, DM/PM or SSc. The proportions of women were higher in all SRD except in AS. Patients with OA or pneumonia were older than those with SRD. The majority of OA patients were female, whereas most of those with pneumonia were male (Table 1). Disease-specific characteristics are characterized in Supplementary Table S1. 
Table 1

Baseline characteristics of patients with systemic rheumatic diseases, OA and pneumonia

\begin{tabular}{|c|c|c|c|c|c|c|c|c|}
\hline & $\begin{array}{l}\text { RA } \\
(n= \\
268)\end{array}$ & $\begin{array}{l}\text { SLE } \\
(n= \\
150)\end{array}$ & $\begin{array}{l}\text { SSc } \\
(n= \\
110)\end{array}$ & $\begin{array}{l}\text { AOSD } \\
(n= \\
107)\end{array}$ & $\begin{array}{l}\text { DM/PM } \\
(n= \\
126)\end{array}$ & $\begin{array}{l}\text { AS } \\
(n= \\
200)\end{array}$ & $\begin{array}{l}O A \\
(n= \\
130)\end{array}$ & $\begin{array}{l}\text { Pneumonia } \\
(n=100)\end{array}$ \\
\hline Age, years & $\begin{array}{l}51.6 \pm \\
12.9\end{array}$ & $\begin{array}{l}32.2 \pm \\
13.5\end{array}$ & $\begin{array}{l}48.7 \pm \\
13.4\end{array}$ & $\begin{array}{l}45.8 \pm \\
16.4\end{array}$ & $\begin{array}{l}49.3 \pm \\
13.7\end{array}$ & $\begin{array}{l}31.9 \pm \\
12.5\end{array}$ & $\begin{array}{l}57.7 \pm \\
7.3\end{array}$ & $68.3 \pm 15.6$ \\
\hline Female, n (\%) & $\begin{array}{l}223 \\
(83.2)\end{array}$ & $\begin{array}{l}122 \\
(81.3)\end{array}$ & $\begin{array}{l}96 \\
(87.3)\end{array}$ & $\begin{array}{l}70 \\
(65.4)\end{array}$ & $\begin{array}{l}89 \\
(70.6)\end{array}$ & $\begin{array}{l}63 \\
(31.5)\end{array}$ & $\begin{array}{l}119 \\
(91.5)\end{array}$ & $33(33.0)$ \\
\hline $\begin{array}{l}\text { WBC count, } x \\
10^{3} / \mathrm{mm}^{3}\end{array}$ & $\begin{array}{l}7.7 \pm \\
2.2\end{array}$ & $\begin{array}{l}4.8 \pm \\
2.5\end{array}$ & $\begin{array}{l}6.9 \pm \\
2.1\end{array}$ & $\begin{array}{l}15.1 \pm \\
9.6\end{array}$ & $\begin{array}{l}7.4 \pm \\
3.9\end{array}$ & $\begin{array}{l}6.8 \pm \\
1.8\end{array}$ & $\begin{array}{l}6.9 \pm \\
5.2\end{array}$ & $11.1 \pm 0.5$ \\
\hline $\begin{array}{l}\text { ANC, } \times \\
10^{3} / \mathrm{mm}^{3}\end{array}$ & $\begin{array}{l}5.0 \pm \\
2.0\end{array}$ & $\begin{array}{l}3.3 \pm \\
2.2\end{array}$ & $\begin{array}{l}4.1 \pm \\
1.8\end{array}$ & $\begin{array}{l}12.5 \pm \\
8.7\end{array}$ & $\begin{array}{l}5.4 \pm \\
3.7\end{array}$ & $\begin{array}{l}4.0 \pm \\
1.5\end{array}$ & $\begin{array}{l}3.7 \pm \\
2.8\end{array}$ & $8.8 \pm 4.4$ \\
\hline $\begin{array}{l}\text { ALC, } \times \\
10^{3} / \mathrm{mm}^{3}\end{array}$ & $\begin{array}{l}1.9 \pm \\
7.0\end{array}$ & $\begin{array}{l}1.1 \pm \\
6.3\end{array}$ & $\begin{array}{l}2.0 \pm \\
6.1\end{array}$ & $\begin{array}{l}1.4 \pm \\
1.6\end{array}$ & $\begin{array}{l}1.3 \pm \\
0.7\end{array}$ & $\begin{array}{l}2.2 \pm \\
0.7\end{array}$ & $\begin{array}{l}2.5 \pm \\
2.1\end{array}$ & $1.3 \pm 0.7$ \\
\hline $\begin{array}{l}\text { AMC, } \times \\
10^{3} / \mathrm{mm}^{3}\end{array}$ & $\begin{array}{l}5.4 \pm \\
2.2\end{array}$ & $\begin{array}{l}3.4 \pm \\
1.8\end{array}$ & $\begin{array}{l}0.5 \pm \\
0.2\end{array}$ & $\begin{array}{l}0.7 \pm \\
0.7\end{array}$ & $\begin{array}{l}0.6 \pm \\
0.3\end{array}$ & $\begin{array}{l}0.5 \pm \\
0.2\end{array}$ & $\begin{array}{l}0.5 \pm \\
0.4\end{array}$ & $0.8 \pm 0.5$ \\
\hline $\begin{array}{l}\text { Leucocytosis }^{a} \text {, } \\
\text { n (\%) }\end{array}$ & $\begin{array}{l}41 \\
(15.3)\end{array}$ & $8(5.4)$ & $5(4.6)$ & $\begin{array}{l}74 \\
(69.2)\end{array}$ & $\begin{array}{l}24 \\
(19.2)\end{array}$ & $\begin{array}{l}11 \\
(5.5)\end{array}$ & $2(1.5)$ & $55(55.0)$ \\
\hline $\begin{array}{l}\text { Hemoglobin, } \\
\mathrm{g} / \mathrm{dL}\end{array}$ & $\begin{array}{l}12.4 \pm \\
1.5\end{array}$ & $\begin{array}{l}10.9 \pm \\
2.2\end{array}$ & $\begin{array}{l}12.9 \pm \\
1.5\end{array}$ & $\begin{array}{l}10.9 \pm \\
1.6\end{array}$ & $\begin{array}{l}12.3 \pm \\
1.8\end{array}$ & $\begin{array}{l}14.4 \pm \\
1.5\end{array}$ & $\begin{array}{l}13.1 \pm \\
1.2\end{array}$ & $11.7 \pm 1.7$ \\
\hline $\begin{array}{l}\text { Platelet count, } \\
\times 10^{3} / \mathrm{mm}^{3}\end{array}$ & $\begin{array}{l}304.7 \\
\pm 85.2\end{array}$ & $\begin{array}{l}180.9 \\
\pm 93.9\end{array}$ & $\begin{array}{l}261.9 \\
\pm 76.0\end{array}$ & $\begin{array}{l}302.8 \\
\pm \\
145.6\end{array}$ & $\begin{array}{l}240.6 \pm \\
93.5\end{array}$ & $\begin{array}{l}256.0 \\
\pm 59.6\end{array}$ & $\begin{array}{l}253.4 \\
\pm 55.6\end{array}$ & $\begin{array}{l}294.7 \pm \\
140.5\end{array}$ \\
\hline $\mathrm{ESR}, \mathrm{mm} / \mathrm{hr}$ & $\begin{array}{l}45.5 \pm \\
30.6\end{array}$ & $\begin{array}{l}47.3 \pm \\
34.2\end{array}$ & $\begin{array}{l}27.8 \pm \\
26.0\end{array}$ & $\begin{array}{l}71.2 \pm \\
31.0\end{array}$ & $\begin{array}{l}40.8 \pm \\
24.8\end{array}$ & $\begin{array}{l}11.0 \pm \\
12.8\end{array}$ & $\begin{array}{l}15.7 \pm \\
13.3\end{array}$ & $71.4 \pm 30.0$ \\
\hline $\mathrm{CRP}, \mathrm{mg} / \mathrm{dL}$ & $\begin{array}{l}2.0 \pm \\
3.3\end{array}$ & $\begin{array}{l}1.5 \pm \\
3.1\end{array}$ & $\begin{array}{l}0.6 \pm \\
1.3\end{array}$ & $\begin{array}{l}11.3 \pm \\
7.9\end{array}$ & $\begin{array}{l}1.8 \pm \\
3.5\end{array}$ & $\begin{array}{l}0.08 \pm \\
0.1\end{array}$ & $\begin{array}{l}0.1 \pm \\
0.3\end{array}$ & $12.4 \pm 9.2$ \\
\hline Albumin, $\mathrm{g} / \mathrm{dL}$ & $\begin{array}{l}4.0 \pm \\
0.4\end{array}$ & $\begin{array}{l}3.2 \pm \\
0.8\end{array}$ & $\begin{array}{l}4.0 \pm \\
0.5\end{array}$ & $\begin{array}{l}3.2 \pm \\
0.5\end{array}$ & $\begin{array}{l}3.5 \pm \\
0.7\end{array}$ & $\begin{array}{l}4.5 \pm \\
0.3\end{array}$ & $\begin{array}{l}4.4 \pm \\
0.2\end{array}$ & $3.2 \pm 0.6$ \\
\hline \multicolumn{9}{|c|}{ Values represent the mean \pm SD or $n(\%)$} \\
\hline \multicolumn{9}{|c|}{$\begin{array}{l}\text { ALC, absolute lymphocyte count; AMC, absolute monocyte count; ANC, absolute neutrophil count; } \\
\text { AOSD, adult onset Still's disease; AS, ankylosing spondylitis; Cl, confidence interval; CRP, C-reactive } \\
\text { protein; DM/PM, dermatomyositis/polymyositis; ESR, erythrocyte sedimentation rate, OA, } \\
\text { Osteoarthritis; RA, rheumatoid arthritis; SLE, systemic lupus erythematosus; SSc, systemic sclerosis; } \\
\text { WBC, white blood cell. }\end{array}$} \\
\hline \multicolumn{9}{|c|}{ a Leucocytosis was defined as a WBC count $\geq 10000 / \mathrm{mm}^{3}$. } \\
\hline
\end{tabular}




\section{Profile of common inflammatory markers in SRDs}

WBC counts in the majority of SRDs were within normal limits and were comparable with those for OA. Patients with AOSD had the highest mean WBC counts, whereas patients with SLE had the lowest (Table 1 and Fig. 1A). Leukocytosis (defined as a WBC count $\geq 10000 / \mathrm{mm}^{3}$ ) was relatively rare; it was detected in only $17 \%$ of patients with all SRDs. Leukocytosis was more common in patients with AOSD than in patients with pneumonia ( $69.2 \%$ vs. $55.0 \%$, respectively; $p=0.04)$. By contrast, $43.3 \%$ and $75.8 \%$ of SLE patients had leukopenia (defined as a WBC count $<4000 / \mathrm{mm}^{3}$ ) and lymphopenia (WBC < $\left.1500 / \mathrm{mm}^{3}\right)$, respectively.

ESR varied between and within SRD groups. With the exception of AS patients, more patients with SRDs than with OA had an elevated ESR (defined by ESR $>20 \mathrm{~mm} / \mathrm{hr}$ ). Elevated ESR was rare in AS (13.5\%) and was less common in patients with SSc (48.6\%) than in those with other SRDs. Only patients with AOSD had high mean ESR levels comparable with those in patients with pneumonia (Table 1 and Fig. 1B).

CRP levels also varied markedly between and within SRDs. Elevated CRP (defined as $>0.5 \mathrm{mg} / \mathrm{dL}$ ) was most common in patients with AOSD (99.1\%), followed by those with RA (57.1\%) and IIM (44.0\%). Only $31.5 \%$ of patients with SLE and $15.6 \%$ of those with SSc had elevated CRP levels. The mean CRP level was highest in AOSD followed by RA, whereas CRP was elevated only slightly in SLE, DM/PM and SSC (Table 1 and Fig. 1C).

\section{Association between CRP and ESR in SRDs}

ESR correlated significantly with CRP level in all SRD groups, albeit to varying degrees (Fig. 2 and Supplementary Table S2). Among all SRD groups, the strongest positive correlation was observed for RA $(r=0.53, p<0.001)$, whereas the weakest was observed for SLE $(r=0.21, p=0.03)$. Furthermore, the correlation between CRP and ESR levels was significantly higher for RA than for SLE (z-test, $p<0.001)$. The strength of the correlation between CRP and ESR for AOSD was comparable with that for pneumonia $(r=0.32$ for AOSD and $r=0.34$ for pneumonia; $z$-test, $p=0.44$ ).

Multivariable linear regression also identified a significant association between CRP and ESR levels in all SRD groups after adjusting for age and gender (Table 2). The ratio of CRP change to ESR change (i.e., $\triangle \mathrm{CRP} / \triangle \mathrm{ESR})$ was the highest for AOSD $(\beta=0.08)$, followed by RA $(\beta=0.06)$ and $\mathrm{DM} / \mathrm{PM}(\beta=0.06)$. By contrast, the ratio was low for SLE $(\beta=0.02)$ and SSc $(\beta=0.02)$. 
Table 2

Association between inflammatory markers in systemic rheumatic diseases using linear regression models.

Crude model

B $\quad 95 \% \mathrm{Cl}$

\section{Age- and sex-adjusted model}

p-value $\quad \beta \quad 95 \% \mathrm{Cl} \quad$ p-value

CRP and ESR

\begin{tabular}{lllllll|}
\hline RA & 0.06 & $0.05-0.07$ & $<0.001$ & 0.06 & $0.05-0.08$ & $<0.001$ \\
\hline SLE & 0.02 & $0.002-0.04$ & 0.03 & 0.02 & $0.002-0.04$ & 0.03 \\
\hline DM/PM & 0.06 & $0.03-0.08$ & $<0.001$ & 0.06 & $0.03-0.08$ & $<0.001$ \\
\hline SSc & 0.03 & $0.01-0.04$ & $<0.001$ & 0.02 & $0.01-0.03$ & $<0.001$ \\
\hline AS & 0.002 & $0.001-0.003$ & 0.003 & 0.002 & $0.001-0.004$ & 0.001 \\
\hline AOSD & 0.08 & $0.03-0.12$ & 0.002 & 0.08 & $0.03-0.13$ & 0.001 \\
\hline OA & 0.01 & $0.004-0.01$ & $<0.001$ & 0.01 & $0.004-0.01$ & $<0.001$ \\
\hline Pneumonia & 0.11 & $0.05-0.16$ & 0.001 & 0.10 & $0.04-0.16$ & 0.04 \\
\hline WBC count ${ }^{\mathrm{a}}$ and $\mathrm{CRP}$ & & & & & \\
\hline RA & 0.17 & $0.09-0.26$ & $<0.001$ & 0.13 & $0.04-0.21$ & 0.003 \\
\hline DM/PM & 0.53 & $0.34-0.73$ & $<0.001$ & 0.53 & $0.33-0.73$ & $<0.001$ \\
\hline AS & 2.76 & $0.80-4.72$ & 0.01 & 2.76 & $0.79-4.72$ & 0.01 \\
\hline AOSD & 0.30 & $0.07-0.53$ & 0.01 & 0.29 & $0.06-0.52$ & 0.01 \\
\hline OA & 2.00 & $1.07-2.86$ & $<0.001$ & 2.06 & $1.14-3.00$ & $<0.001$ \\
\hline Pneumonia & 0.21 & $0.10-0.31$ & $<0.001$ & 0.20 & $0.08-0.31$ & 0.001 \\
\hline AOSD & & & & & & \\
\hline
\end{tabular}

AOSD, adult onset Still's disease; AS, ankylosing spondylitis; $\mathrm{Cl}$, confidence interval; CRP, C-reactive protein; DM/PM, dermatomyositis/polymyositis; ESR, erythrocyte sedimentation rate, OA, osteoarthritis; RA, rheumatoid arthritis; SLE, systemic lupus erythematosus; SSc, systemic sclerosis; WBC, white blood cell.

Linear regression was performed using CRP and WBC counts as dependent variables.

a WBC count, $\times 10^{3} / \mathrm{mm}^{3}$.

\section{Dissociation between WBC count and acute phase reactant levels in SRDs}

A significant but weak correlation between WBC count and ESR level was noted only in patients with AS (Fig. 2 and Supplementary Table S2). WBC counts significantly correlated with CRP levels in AOSD, RA 
and DM/PM, with the greatest correlation observed for DM/PM $(r=0.47, p<0.001)$. There was no significant correlation between WBC count and CRP level in SLE or SSc.

WBC counts were also associated significantly with CRP levels both in crude and adjusted regression models (Table 2). The ratio of WBC count change to CRP change ( $\triangle \mathrm{WBC} / \triangle \mathrm{CRP})$ was weaker for RA $(\beta=$ $0.13)$, similar for AOSD $(\beta=0.29)$ and stronger for $D M / P M(\beta=0.53)$ than that for pneumonia $(\beta=0.20)$.

\section{Predictive values of inflammatory markers for diagnosis of SRDs}

Finally, we performed ROC analysis to evaluate the ability of ESR, CRP levels and WBC counts to discriminate SRDs from OA. Comparing the predictive values of inflammatory markers for diagnosis of SRDs, the AUC for ESR and CRP were similar, whereas the AUC for WBC count was less than that of ESR or CRP in most SRDs (Fig. 3). The AUC for ESR or CRP was relatively high for AOSD, RA, DM/PM and SLE, but not for SSc and AS. The AUC $(95 \% \mathrm{Cl})$ for WBC counts was $0.89(0.85-0.94)$ for AOSD and 0.68 (0.63-0.74) for RA. Interestingly, the AUC for WBC in SLE $(0.22 ; 95 \% \mathrm{Cl}, 0.15-0.28)$ was lower than 0.50 , suggesting that leukopenia is associated with SLE. The optimal cut-off values for ESR and CRP were, however, within or slightly above the normal limit (i.e., $<20 \mathrm{~mm} / \mathrm{hr}$ for ESR and $<0.5 \mathrm{mg} / \mathrm{dL}$ for CRP) (Supplementary table S3).

\section{Discussion}

To the best of our knowledge, this is the first report to analyse routine inflammatory markers (ESR, CRP and leukocytosis) in treatment-naïve patients with SRDs. Most SRDs were associated with an increased ESR, whereas elevation of CRP was observed in only a few SRDs. Leukocytosis was uncommon in most patients with SRD. The degree of correlation between ESR and CRP varied markedly among SRDs. For most SRDs, WBC counts were not associated with ESR or CRP.

The human immune system responds differently to two major types of infection, namely, bacterial and viral infections. Acute bacterial infection induces production of interleukin (IL)-1, IL-6, tumour necrosis factor (TNF)-a and granulocyte-(macrophage) colony-stimulating factor (G(M)-CSF) along with preferential recruitment of myeloid cells; by contrast, viral infection promotes generation of interferon (IFN) and mobilises lymphoid cells (18-22). Interestingly, type 1 IFN suppresses innate responses to bacterial infection (23), suggesting that both anti-bacterial and anti-viral immune responses influence each other to generate "optimal" defences by (possibly) conserving limited resources. Particular SRDs such as RA and AOSD simulate an anti-bacterial response, whereas SRDs such as SLE generally mimic an anti-viral response. The type of immune response might depend on the type of cytokines that "drive" each SRD (24). For example, a large amount of type 1 IFN is generated during active SLE, which is a time when immune cells respond to human deoxyribonucleic acid/ribonucleic acid (DNA/RNA) released during tissue damage; this response is similar to responses to viral DNA/RNA. IL- 1 and IL-6 are produced during both AOSD and bacterial infection, and they coordinate the "anti-bacterial" immune response (25). This complex web of different inflammatory cytokines that orchestrate autoimmune responses in SRD is 
further supported by findings that responses to treatments targeting a specific cytokine vary markedly between SRDs. As an example, treatments that neutralize TNF-a are quite effective in RA but not in SLE. In rare cases, TNF-a inhibitor can even exacerbate SLE disease activity $(26,27)$.

The profile of cytokines driving different SRDs is reflected indirectly by CRP and ESR levels. TNF- $a$ and IL6 increase both CRP and ESR, whereas type 1 IFN increases ESR rather than CRP. This disproportionate increase in ESR results, in part, from direct inhibition of hepatic CRP production by type 1 IFN (28). Accordingly, RA and AOSD show a concordant increase in both ESR and CRP, whereas SLE (in which production of type I IFN is dominant) shows a disproportionate increase in ESR (29-31). In addition, SLE is associated with increased production of serum immunoglobulins, which accelerates $\operatorname{ESR}(28,32,33)$. DM is also associated with type I IFN (34-36); thus patients with IIM showed low CRP levels relative to ESR, similar to SLE. Of note, we reported previously that ESR elevation is associated with interstitial lung disease and a worse outcome in patients with DM, rather than with extent of muscle inflammation; this suggests that organ involvement might influence the inflammatory marker profile in a particular SRD (37). AS did not show a significant increase in ESR or CRP when compared with OA. CPR was elevated only in $15.6 \%$ of patients with SSc, whereas ESR was elevated in $48.6 \%$. Whether the relatively low increase in inflammatory markers results from transforming growth factor- $\beta$ should be a subject to further investigations.

Strikingly, leukocytosis was observed in less than $15 \%$ of patients with SRD. Only patients with AOSD, who present with acute systemic inflammation often not distinguishable from an acute bacterial infection, had levels of leukocytosis comparable with those in patients with pneumonia. This scarcity of leukocytosis contradicts the general assumption that leukocytosis is an excellent routine marker of systemic inflammation. In addition, leukopenia was common during active SLE. Therefore, leukocytosis should not be used as the sole marker for assessing systemic inflammation in SRD.

Although ROC analysis revealed that ESR and CRP were good markers for discriminating SRD from a non-inflammatory condition (i.e., OA in this study), the cut-off values were within the normal range (or close to the upper normal limit). Therefore, inflammatory markers might have a limited value for diagnosing SRD. Indeed, in patients with AS or SSc, all three inflammatory markers had a low AUC (< 0.70). However, longitudinal changes of inflammatory markers might be still useful for monitoring disease activity.

A strength of this retrospective observational study is that we analysed inflammatory markers at the time of SRD diagnosis and prior to treatment. This eliminates treatment-related effects on inflammatory markers and thus isolates the impact of disease on these markers. However, it is unclear how these inflammatory markers vary with respect to disease progression in patients receiving or not receiving treatment. Furthermore, the association between longitudinal changes in serum cytokine, chemokine and inflammatory marker levels need to be investigated in a prospective study in which patients do and do not receive treatment. 


\section{Conclusions}

In conclusion, not all common inflammatory markers (ESR, CPR and WBC count) are elevated in SRD. Indeed, individual SRDs are associated with a unique inflammatory marker profile. Until more novel, disease-specific biomarkers of local and systemic inflammation are available, routine inflammatory markers should be interpreted with caution when diagnosing and assessing disease activity in those with SRD.

\section{Abbreviations}

ACR, American College of Rheumatology; AOSD, adult onset Still's disease; AUC, area under the curve; $\mathrm{Cl}$, confidence interval; CRP, C-reactive protein; DM/PM, dermatomyositis/polymyositis; DNA, deoxyribonucleic acid; ESR, erythrocyte sedimentation rate; EULAR, European League Against Rheumatism; G(M)-CSF, granulocyte-(macrophage) colony-stimulating factor; HLA, human leukocyte antigen; IFN, interferon; IL, interleukin; IIM, idiopathic inflammatory myopathy; OA, osteoarthritis; RA, rheumatoid arthritis; RNA, ribonucleic acid; ROC, receiver operator characteristic; SLE, systemic lupus erythematosus; SRD, systemic rheumatic disease; SSc, systemic sclerosis; TNF, tumour necrosis factor; WBC, white blood cell;

\section{Declarations}

\section{Ethics approval and consent to participate}

The study complied with the Declaration of Helsinki and was approved by the Institutional Review Board of Seoul National University Hospital (H-1702-064-831). The requirement for informed consent was waived due to the retrospective nature of study.

\section{Consent for publication}

Not applicable

\section{Availability of data and materials}

The data that support the results of this study are available from the corresponding author, JKP, upon request.

\section{Competing interests}

None of the authors gained any commercial or financial benefit from the work reported. None of the authors have any financial interests that could create a potential conflict of interest or the appearance of a conflict of interest.

\section{Funding}


No specific funding was received from any bodies in the public, commercial or not-for-profit sectors.

\section{Author's contributions}

All authors contributed to the study conception and design. Material preparation, data collection and analysis were performed by all listed co-authors. The first draft of the manuscript was written by MJK and all authors commented on previous versions of the manuscript. All authors read and approved the final manuscript.

\section{Acknowledgements}

Not applicable

\section{References}

1. Zweifach BW, Grant L, McCluskey RT. The inflammatory process: Academic Press; 2014.

2. Gruys E, Toussaint M, Niewold T, Koopmans S. Acute phase reaction and acute phase proteins. J Zhejiang Univ Sci B 2005;6(11):1045.

3. Heinrich PC, Castell JV, Andus T. Interleukin-6 and the acute phase response. Biochem J 1990;265(3):621.

4. Feldman M, Aziz B, Kang GN, Opondo MA, Belz RK, Sellers C. C-reactive protein and erythrocyte sedimentation rate discordance: frequency and causes in adults. Transl Res 2013;161(1):37-43.

5. Keenan R, Swearingen C, Yazici Y. Erythrocyte sedimentation rate and C-reactive protein levels are poorly correlated with clinical measures of disease activity in rheumatoid arthritis, systemic lupus erythematosus and osteoarthritis patients. Clin Exp Rheumatol 2008;26(5):814.

6. Syed KM, Pinals RS. Leukocytosis in rheumatoid arthritis. J Clin Rheumatol 1996;2(4):197-202.

7. Go DJ, Lee EY, Lee EB, Song YW, Konig MF, Park JK. Elevated Erythrocyte Sedimentation Rate Is Predictive of Interstitial Lung Disease and Mortality in Dermatomyositis: a Korean Retrospective Cohort Study. J Korean Med Sci 2016;31(3):389-96.

8. Arnett FC, Edworthy SM, Bloch DA, McShane DJ, Fries JF, Cooper NS, et al. The American Rheumatism Association 1987 revised criteria for the classification of rheumatoid arthritis. Arthritis Rheum 1988;31(3):315-24.

9. Aletaha D, Neogi T, Silman AJ, Funovits J, Felson DT, Bingham CO, et al. 2010 rheumatoid arthritis classification criteria: an American College of Rheumatology/European League Against Rheumatism collaborative initiative. Arthritis Rheum 2010;62(9):2569-81.

10. Hochberg MC. Updating the American College of Rheumatology revised criteria for the classification of systemic lupus erythematosus. Arthritis Rheum 1997;40(9):1725.

11. Linden SVD, Valkenburg HA, Cats A. Evaluation of diagnostic criteria for ankylosing spondylitis. Arthritis Rheum 1984;27(4):361-8. 
12. Hoogen F, Khanna D, Fransen J, Johnson SR, Baron M, Tyndall A, et al. 2013 classification criteria for systemic sclerosis: an American College of Rheumatology/European League against Rheumatism collaborative initiative. Arthritis Rheum 2013;65(11):2737-47.

13. Yamaguchi M, Ohta A, Tsunematsu T, Kasukawa R, Mizushima $Y$, Kashiwagi $H$, et al. Preliminary criteria for classification of adult Still's disease. J Rheumatol 1992;19(3):424-30.

14. Bohan A, Peter JB. Polymyositis and dermatomyositis. N Engl J Med 1975;292(7):344-7.

15. Siemons $L$, ten Klooster PM, Vonkeman HE, van Riel PL, Glas CA, van de Laar MA. How age and sex affect the erythrocyte sedimentation rate and C-reactive protein in early rheumatoid arthritis. BMC Musculoskelet Disord 2014;15(1):368.

16. Lakoski SG, Cushman M, Criqui M, Rundek T, Blumenthal RS, D'Agostino Jr RB, et al. Gender and Creactive protein: data from the Multiethnic Study of Atherosclerosis (MESA) cohort. Am Heart J 2006;152(3):593-8.

17. Ranganath VK, Elashoff DA, Khanna D, Park G, Peter JB, Paulus HE. Age adjustment corrects for apparent differences in erythrocyte sedimentation rate and C-reactive protein values at the onset of seropositive rheumatoid arthritis in younger and older patients. J Rheumtol 2005;32(6):1040-2.

18. Isaacs A, Lindenmann J. Virus interference. I. The interferon. Proc R Soc Lond B Biol Sci 1957;147(927):258-67.

19. Stark GR, Kerr IM, Williams BR, Silverman RH, Schreiber RD. How cells respond to interferons. Annu Rev Biochem 1998;67(1):227-64.

20. Dinarello CA. Proinflammatory cytokines. Chest 2000;118(2):503-8.

21. Pinsky MR, Vincent J-L, Deviere J, Alegre M, Kahn RJ, Dupont E. Serum cytokine levels in human septic shock: relation to multiple-system organ failure and mortality. Chest 1993;103(2):565-75.

22. Holub M, Lawrence DA, Andersen N, Davidová A, Beran O, Marešová V, et al. Cytokines and Chemokines as Biomarkers of Community-Acquired Bacterial Infection. Mediators Inflamm 2013;2013:190145.

23. McNab F, Mayer-Barber K, Sher A, Wack A, O'Garra A. Type I interferons in infectious disease. Nat Rev Immunol 2015;15(2):87-103.

24. O'Shea JJ, Ma A, Lipsky P. Cytokines and autoimmunity. Nat Rev Immunol 2002;2(1):37.

25. Maria AT, Le Quellec A, Jorgensen C, Touitou I, Riviere S, Guilpain P. Adult onset Still's disease (AOSD) in the era of biologic therapies: dichotomous view for cytokine and clinical expressions. Autoimmun Rev 2014;13(11):1149-59.

26. Schett G, Elewaut D, Mclnnes IB, Dayer J-M, Neurath MF. How cytokine networks fuel inflammation: toward a cytokine-based disease taxonomy. Nat Med. 2013;19(7):822-4.

27. Moulis G, Sommet A, Lapeyre-Mestre M, Montastruc J-L. Is the risk of tumour necrosis factor inhibitor-induced lupus or lupus-like syndrome the same with monoclonal antibodies and soluble receptor? A case/non-case study in a nationwide pharmacovigilance database. Rheumatology (Oxford) 2014;53(10):1864-71. 
28. Gaitonde S, Samols D, Kushner I. C-reactive protein and systemic lupus erythematosus. Arthritis Rheum 2008;59(12):1814-20.

29. Honig S, Gorevic P, Weissmann G. C-Reactive Protein in Systemic Lupus Erythematosus. Arthritis Rheum 1977;20(5):1065-70.

30. Becker G, Waldburger M, Hughes G, Pepys M. Value of serum C-reactive protein measurement in the investigation of fever in systemic lupus erythematosus. Ann Rheum Dis 1980;39(1):50-2.

31. Hill AS. C-reactive protein in the chronic rheumatic diseases. The Lancet 1951;258(6688):807-11.

32. Descombes $P$, Schibler U. A liver-enriched transcriptional activator protein, LAP, and a transcriptional inhibitory protein, LIP, are translated from the sam mRNA. Cell 1991;67(3):569-79.

33. Honda Y, Rogers L, Nakata K, Zhao B-Y, Pine R, Nakai Y, et al. Type I interferon induces inhibitory 16kD CCAAT/enhancer binding protein (C/EBP) $\beta$, repressing the HIV-1 long terminal repeat in macrophages: pulmonary tuberculosis alters C/EBP expression, enhancing HIV-1 replication. J Exp Med 1998;188(7):1255-65.

34. Greenberg SA. Type 1 interferons and myositis. Arthritis Res Ther 2010;12 Suppl 1(Suppl 1):S4-S.

35. Greenberg SA. Dermatomyositis and type 1 interferons. Curr Rheumatol Rep 2010;12(3):198-203.

36. Salajegheh M, Kong SW, Pinkus JL, Walsh RJ, Liao A, Nazareno R, et al. Interferon-stimulated gene 15 (ISG15) conjugates proteins in dermatomyositis muscle with perifascicular atrophy. Ann Neurol 2010;67(1):53-63.

37. Park JK, Gelber AC, George M, Danoff SK, Qubti MA, Christopher-Stine L. Pulmonary impairment, not muscle injury, is associated with elevated ESR in the idiopathic inflammatory myopathies. Rheumatology (Oxford) 2013;52(7):1336-8.

\section{Figures}
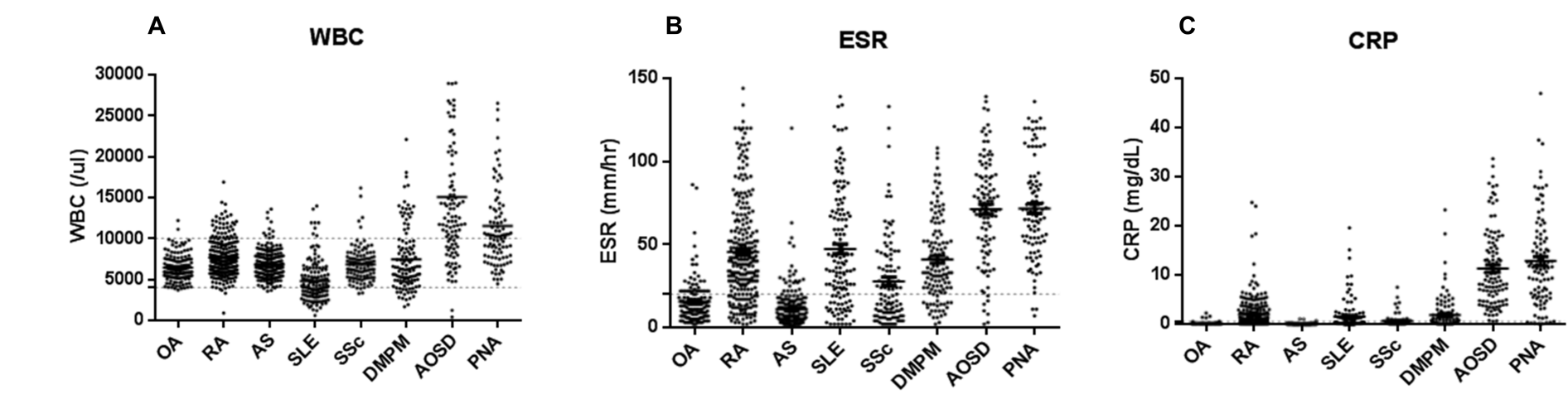

WBC>10K (\%)

ESR>20

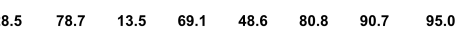

CRP>0.5
mg/dL (\%)

Figure 2

Profiles of inflammatory markers in patients with systemic rheumatic diseases, OA or pneumonia. (A) WBC count; (B) ESR; (C) CRP. The horizontal lines indicate the upper and lower limit of normal. AOSD, 
adult onset Still's disease; AS, ankylosing spondylitis; Cl, confidence interval; CRP, C-reactive protein; DM/PM, dermatomyositis/polymyositis; ESR, erythrocyte sedimentation rate, OA, osteoarthritis; PNA, pneumonia; RA, rheumatoid arthritis; SLE, systemic lupus erythematosus; SSc, systemic sclerosis; WBC, white blood cell.
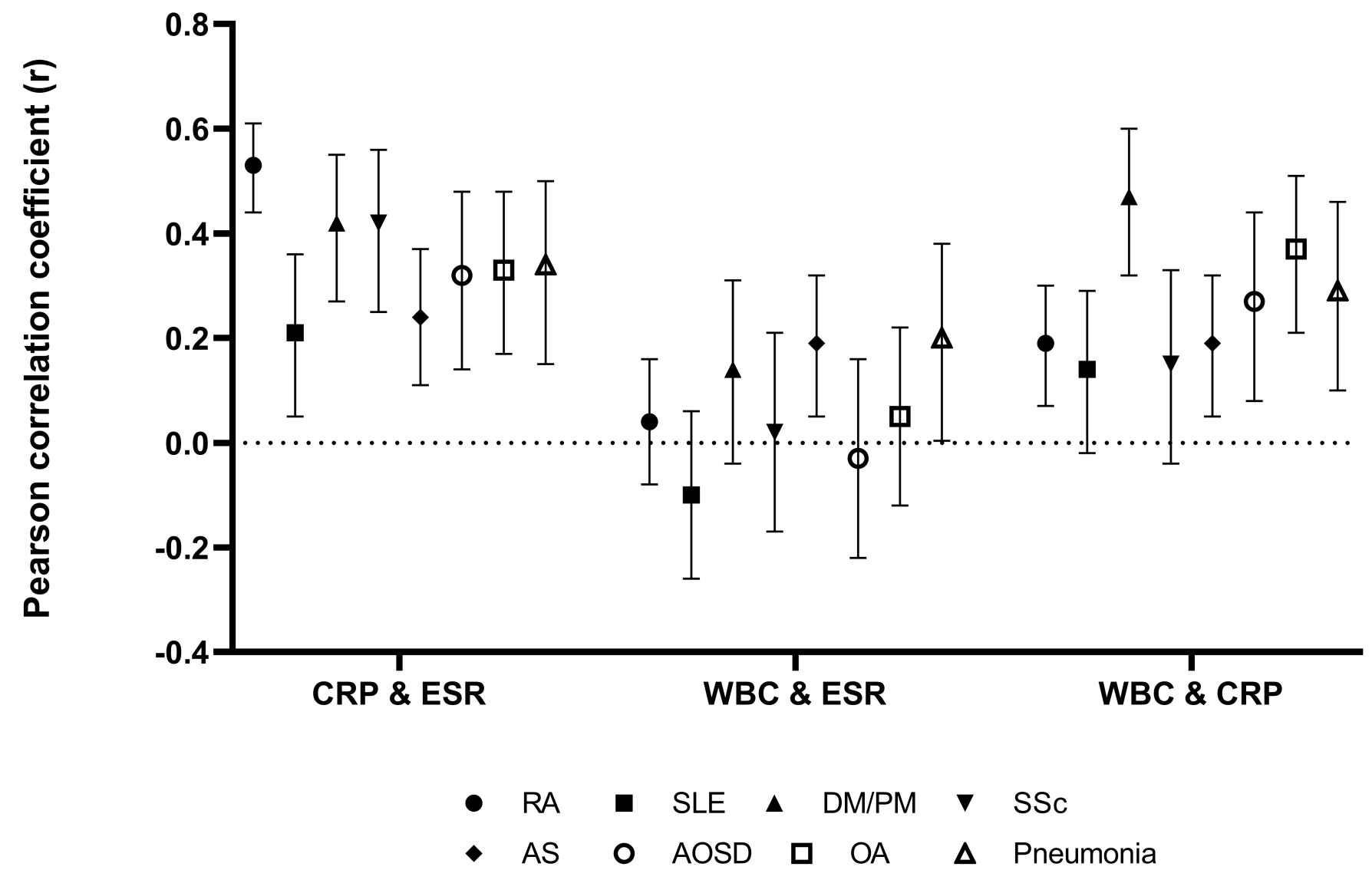

Figure 4

Correlation among inflammatory markers in patients with systemic rheumatic diseases, OA and pneumonia. Correlation between CRP and ESR (left), between WBC and ESR (middle), and between WBC and CRP (right) in each SRD, OA and pneumonia. Correlation analysis was performed by calculating Pearson's correlation coefficient. Whiskers indicate 95\% confidence intervals. AOSD, adult onset Still's disease; AS, ankylosing spondylitis; CRP, C-reactive protein; DM/PM, dermatomyositis/polymyositis; ESR, erythrocyte sedimentation rate, OA, osteoarthritis; RA, rheumatoid arthritis; SLE, systemic lupus erythematosus; SSc, systemic sclerosis; WBC, white blood cell. 

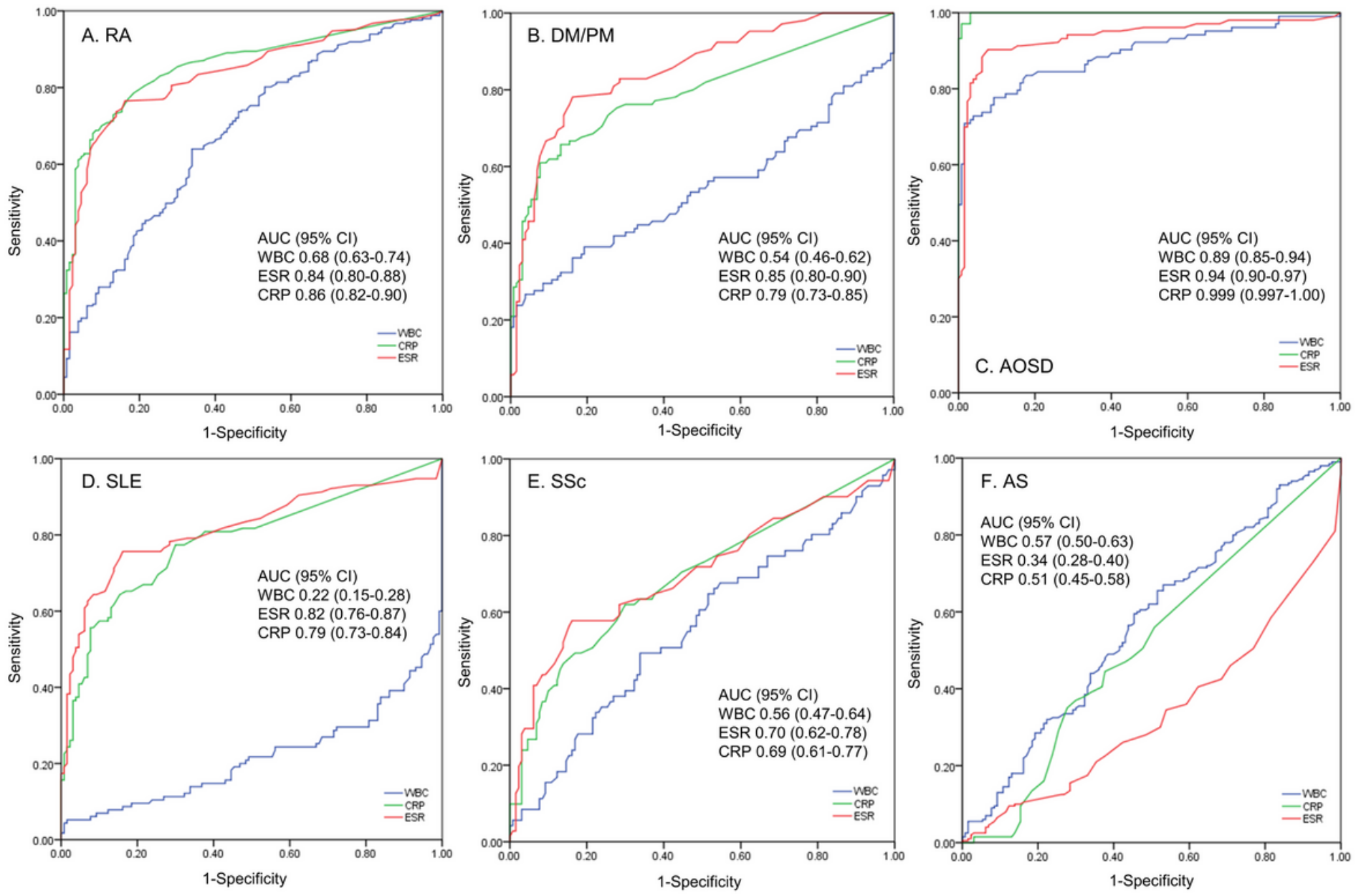

\section{Figure 5}

Prediction of inflammatory markers for systemic rheumatic diseases. Receiver operating characteristic analysis of the utility of ESR, CRP and WBC as predictors of systemic rheumatic diseases versus osteoarthritis. AOSD, adult onset Still's disease; AUC, area under the curve; AS, ankylosing spondylitis; CRP, C-reactive protein; DM/PM, dermatomyositis/polymyositis; ESR, erythrocyte sedimentation rate, RA, rheumatoid arthritis; SLE, systemic lupus erythematosus; SSc, systemic sclerosis; WBC, white blood cell.

\section{Supplementary Files}

This is a list of supplementary files associated with this preprint. Click to download.

- Suppl.File.docx

- Suppl.File.docx 